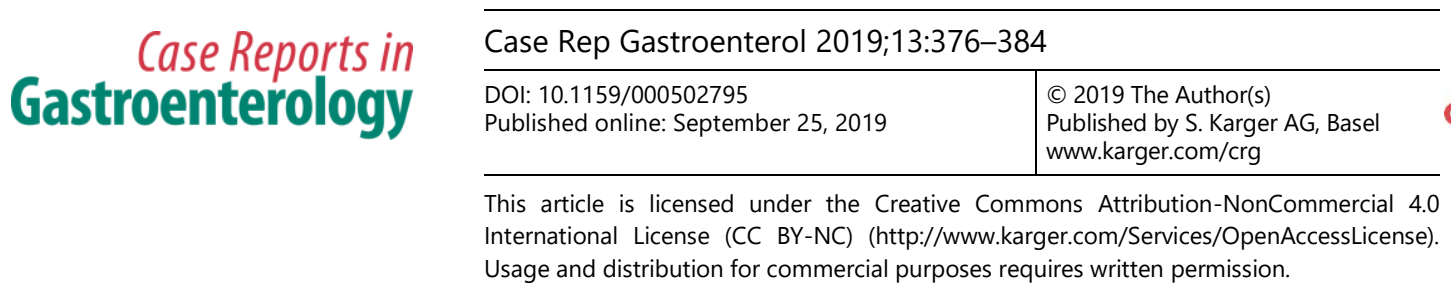

\title{
Low-Stage Gastric MALT Lymphoma Causing Life-Threatening Upper Gastrointestinal Bleeding
}

\author{
Muhammad Begawan Bestari ${ }^{a} \quad$ Ivonne Golda Palungkun $^{b}$ \\ Bethy Suryawathy Hernowo ${ }^{c}$ Siti Aminah Abdurachman ${ }^{a}$ \\ Eka Surya Nugraha ${ }^{a}$ \\ ${ }^{a}$ Division of Gastroenterohepatology, Department of Internal Medicine, Hasan Sadikin \\ General Hospital-Faculty of Medicine, University of Padjadjaran, Bandung, Indonesia; \\ ${ }^{b}$ Department of Anatomic Pathology, Santo Borromeus Hospital, Bandung, Indonesia; \\ 'Department of Anatomic Pathology, Hasan Sadikin General Hospital-Faculty of Medicine, \\ University of Padjadjaran, Bandung, Indonesia
}

\section{Keywords}

Upper gastrointestinal bleeding · Mucosa-associated lymphoid tissue lymphoma .

Helicobacter pylori $\cdot$ Urgent endoscopy

\begin{abstract}
Gastric mucosa-associated lymphoid tissue (MALT) lymphoma is an uncommon tumor of the stomach that only comprises around $1-6 \%$ of all tumors of the stomach. Non-Hodgkin lymphoma more commonly affects the lymph nodes and may spread to the spleen and bone marrow, whereas extranodal non-Hodgkin lymphoma is less common. Primary gastric lymphoma is further divided based on histologic features; one of the types is MALT lymphoma, which is strongly associated with Helicobacter pylori infection. The first sign of the disease is usually mimicking gastritis. However, in the case reported here, the first sign of gastric MALT lymphoma was massive gastrointestinal (GI) bleeding with hemodynamic instability in a 75year-old male. The patient came to the emergency department and was immediately resuscitated, intubated, and admitted to the intensive care unit. Urgent endoscopy $(<6 \mathrm{~h})$ was done to identify the source of bleeding, which were oozing ulcerated polypoid masses; endoscopic hemostasis was done, which successfully stopped the bleeding. However, the next day,
\end{abstract}


rebleeding occurred and a second endoscopic hemostasis was performed. The bleeding stopped and the patient showed gradual improvement. The biopsy result of a gastric MALT lymphoma of grade IE1 with $H$. pylori infection warranted a treatment regimen for Helicobacter eradication. The patient recovered, with follow-up endoscopy at 3 months, at 6 months, and yearly thereafter with no sign of recurrence. This case shows that gastric MALT lymphoma, even at a low stage (1E1), can cause life-threatening upper GI bleeding that requires aggressive resuscitation and urgent endoscopy.

(C) 2019 The Author(s)

Published by S. Karger AG, Basel

\section{Introduction}

Massive upper gastrointestinal (GI) bleeding is a life-threatening emergency condition that requires intervention as soon as possible. The most common cause of upper GI bleeding are ulcers [1], whereas malignancies - especially hematologic in origin [2], in our case lymphomas - rarely cause upper GI bleeding. Lymphomas more commonly affect the lymph nodes and can spread to the spleen and bone marrow. Extranodal lymphoma of the non-Hodgkin type accounts for $24-48 \%$ of all lymphoma cases [3]. The GI tract is the most common site of extranodal lymphoma, estimated to be the site of around $30-45 \%$ of all extranodal lymphomas; the stomach is the most common site [4].

Histologically, primary gastric lymphoma is divided into several different types according to the Revised European-American Classification of Lymphoid Neoplasms (REAL), with diffuse large B-cell lymphoma being the most common (comprising $59 \%$ of the cases), followed by mucosa-associated lymphoid tissue (MALT) lymphoma in 38\% of the cases [5]. Primary gastric lymphoma is a rare disease, comprising only about $1-6 \%$ of all tumors of the stomach [4]. Gastric lymphoma originating from MALT is strongly related to Helicobacter pylori infection or chronic antigenic stimulation.

In this case report, we present a gastric MALT lymphoma causing massive upper GI bleeding and rebleeding after endoscopy hemostasis. To the best of our knowledge, this is the first massive gastric bleeding arising from MALT lymphoma reported from Indonesia.

\section{Case Presentation}

A 75-year-old male presented to the emergency department with $6 \mathrm{~h}$ of severe upper GI bleeding and syncope with no abdominal pain. Current medications included acetylsalicylic acid (80 mg daily for the past 20 years), amlodipine, atorvastatin, and celecoxib $200 \mathrm{mg}$ as needed for joint pain, which had been stopped 2 weeks before he was admitted to the hospital. His past medical history revealed a history of hypertension and osteoarthritis. There was no history of smoking and alcohol consumption, and there was no personal or family history of GI bleeding or esophageal or gastric cancer.

Pertinent physical examination findings showed a blood pressure of 70/40 $\mathrm{mm} \mathrm{Hg}$, a heart rate of $120 \mathrm{bpm}$, and oxygen saturation of $90 \%$ on room air. There were no stigmata of chronic liver disease. Abdominal examination demonstrated a soft abdomen that was nontender and nondistended, with normal bowel sounds. Rectal examination showed melena. Laboratory examination results showed hemoglobin at $6 \mathrm{~g} / \mathrm{dL}$, a hematocrit of $23 \%$, a platelet count of $240,000 / \mathrm{mm}^{3}$, a prothrombin time INR of 1.1 , and blood urea nitrogen at $30 \mathrm{mg} / \mathrm{dL}$.

Based on a Glasgow-Blatchford score (GBS) of 19, the patient was intubated and admitted to the intensive care unit (ICU). Initial resuscitation was performed, including IV access with 
two large-bore catheters, volume replacement (crystalloid), and transfusion of typed and cross-matched packed red blood cells; 6 units were given during the hospital stay. Pantoprazole was initiated with an $80-\mathrm{mg}$ bolus intravenously and $8 \mathrm{mg} / \mathrm{h}$ continuous infusion thereafter for $72 \mathrm{~h}$.

Esophagoduodenoscopy was performed within $6 \mathrm{~h}$; there were bleedings all over the stomach, as shown in the gastric body and fundus (Fig. 1a and b, respectively), which were then flushed away with a water jet through an auxiliary water channel (endoscope Olympus ${ }^{\circledR}$ GIF-1T Q160), and all the blood was sucked out using a special suction connector (Fig. 1c). Oozing ulcerated polypoid masses were found in the gastric body (Fig. 1d). Endoscopic treatment was applied with 1-mL aliquots of 1:10,000 epinephrine injected 4 times at the base of the ulcer, and argon plasma coagulation was applied to the vessel and ulcer base. The bleeding was then stopped successfully.

However, on the following day, there was bright-red blood in a gastric aspirate, and a second endoscopy was performed, which showed rebleeding of the ulcers (Fig. 1e). Hemospray ${ }^{\circledR}$ (Cook Medical, Winston-Salem, NC, USA) was then applied to the ulcers to control the bleeding.

The patient remained in the ICU for $72 \mathrm{~h}$ after endoscopy; there was no further bleeding, and a third endoscopy using chromoendoscopy was performed to evaluate the ulcers. Endoscopic ultrasound was performed to evaluate the extension of the tumor, which showed that the tumor was confined to the submucosa of the stomach (Fig. 1f). Multiple biopsies were taken from the ulcers, which showed tumor cells (Fig. 2a) and H. pylori (Fig. 2b). The pathology of the ulcers was characterized by marginal zone cells infiltrating the lamina propria in a diffuse pattern and colonizing the reactive germinal center. Immunohistochemical stains showed that these cells were reactive to CD20 (Fig. 2c), CD43, and BCL-2 antibodies, and nonreactive to cyclin D1 and CD3 (Fig. 2d), which is consistent with MALT lymphoma (low-grade B-cell lymphoma). Based on the imaging and histopathologic examination, the tumor was identified as primary gastric MALT lymphoma (stage IE1)

The patient was treated with $H$. pylori eradication therapy (twice-daily triple combination of pantoprazole $40 \mathrm{mg}$, amoxicillin $1 \mathrm{~g}$, and clarithromycin $500 \mathrm{mg}$ for 2 weeks). H. pylori eradication follow-up using a urea breath test was negative 2 weeks after the end of therapy. A follow-up endoscopy performed after 3 months showed that the ulcers had healed (Fig. 3). After 6 months, the gastric mucosa was completely healed. The patient is scheduled for yearly endoscopy for early relapse detection. The last follow-up was in 2018 (3 years after treatment) and showed unremarkable results.

\section{Discussion and Conclusion}

In our case, massive upper GI bleeding with severe hematemesis and hemodynamical instability were the most prominent symptoms [6]. Ulcers are the most common etiology of upper GI bleeding (59\%), compared to malignancies (2-4\%) [1]. Gastric MALT lymphoma has been reported to manifest as upper GI bleeding upon diagnosis in only $15.6 \%$ of the cases [4]. The presentation of massive bleeding with hypovolemic shock is very rare as the first sign of gastric MALT lymphoma, especially in an early stage - in this case, stage IE. The only similar case was reported by Obleagă et al. [7] in 2017, with a more advanced tumor stage of IIE, in which, after esophagoduodenoscopy, they had to resort to surgery for gastrectomy and duodenostomy due to bleeding and the size of the tumor. 
Regarding our patient, we decided to perform urgent endoscopy $(<6 \mathrm{~h})$, considering that he was a high-risk patient with a GBS of 19 and hemodynamically unstable. Urgent endoscopy on high-risk patients has recently been described as an independent predictor of lower mortality rates; current guidelines also state that for acute overt nonvariceal upper GI bleeding in high-risk patients such as those who are hemodynamically unstable, very early endoscopy $(<12 \mathrm{~h})$ is recommended $[1,8]$. The difficulty that we encountered during urgent endoscopy was due to the massive upper GI bleeding, with massive amounts of blood in the gastric body and fundus; thus, visualization was limited. We used specific equipment to flush out the blood, using an Olympus ${ }^{\circledR}$ GIF-1T Q160 endoscope with a 3.7-mm working channel and a special suction connector (Fig. 1c). The blood and clots were successfully removed within minutes, allowing the identification of the source of the bleeding, and subsequently performed the appropriate hemostatic procedure.

The bleeding, which originated from oozing ulcerated polypoid masses, was successfully stopped after endoscopic hemostasis by epinephrine injection and argon plasma coagulation. For patients with actively bleeding ulcers, thermal therapy is preferred in order to achieve initial hemostasis, since prospective randomized trials have demonstrated that this lowers the need for urgent surgery, bleeding, transfusions, and the length of hospital stay. Epinephrine injection, when used in combination, also reduces the risk of rebleeding and surgery $[9,10]$.

The diagnosis for our patient was established by biopsy and histopathologic examination with immunohistochemical staining and identification of H. pylori. Gastric MALT lymphoma is a clonal B-cell neoplasm that arises from post-germinal center B cells in the marginal zone of lymphoid follicles. H. pylori infection is considered a major cause of chronic active gastritis and a major risk factor for gastric MALT lymphoma [11]. It has been discovered that only one of 13 of the $H$. pylori strains has the ability to stimulate B-cell proliferation and the production of IL-2 by T cells. High expression of APRIL (a proliferation-inducing ligand) is believed to have a vital role in sustaining B-cell proliferation. Moreover, $H$. pylori is able to activate extracellular signal-regulated kinase and Bcl-2 expression, which leads to inhibition of apoptosis through translocation of the CagA protein directly into B cells [12]. The prevalence of H. pylori in Indonesia is considered low (approx. 22.1\%) [13] when compared to the global prevalence based on a meta-analysis from 2017 [14]. As a comparison, the prevalence in South-Eastern Asia is reported to be approximately $43.1 \%$. Worldwide, the country with lowest prevalence of H. pylori is Switzerland (18.9\%) [14].

The importance of $H$. pylori eradication therapy was paramount in our case. Current guidelines stated that eradication of H. pylori must be conducted on all gastric MALT lymphomas regardless of the stage, and eradication of $H$. pylori should be the sole initial therapy for localized gastric MALT lymphoma with Helicobacter positivity, which in most patients will result in lymphoma regression and long-term disease control. The therapy regimen includes a combination of a proton pump inhibitor plus clarithromycin with amoxicillin or metronidazole for 10-14 days, which is usually highly effective [15]. Follow-up after therapy by endoscopic examination should be performed 3-6 months after the eradication therapy. Selection of antibiotics must be done selectively due to resistance to antibiotics [12]. Complete remission was achieved in $74.4 \%$ of patients who underwent eradication therapy, after a median time of around 4 months. A study showed that the 3-year and 5-year survival rates were 90.3 and $76.2 \%$, respectively [4]. Even after remission, relapse and reinfection with $H$. pylori should be monitored, as well as the risk of gastric adenocarcinoma, because the risk is 6 -fold increased in patients with gastric MALT compared to the general population [15].

In conclusion, gastric MALT lymphoma remains a rare disease. Our case demonstrated that this type of lymphoma, even at a low grade, could be life-threatening due to massive GI 
bleeding. Endoscopy on such a patient should not be delayed, as it reduces mortality and also allows the early identification of a definitive diagnosis through biopsy so treatment is not delayed. Even though the presentation in our case was very unusual and acute, treatment for low-grade gastric MALT lymphoma with $H$. pylori positivity remains as simple as eradication of $H$. pylori. Follow-up also plays an important role for the early detection of recurrence or emergence of another tumor.

\section{Statement of Ethics}

Informed patient consent was obtained for this publication.

\section{Disclosure Statement}

The authors have no conflicts of interest to declare.

\section{Author Contributions}

M.B. Bestari, S.A. Abdurachman, and E.S. Nugraha wrote and revised the manuscript. I.G. Palungkun and B.S. Hernowo conducted the histopathologic analysis and contributed to the pathology sections.

\section{References}

1 Gralnek IM, Dumonceau JM, Kuipers EJ, Lanas A, Sanders DS, Kurien M, et al. Diagnosis and management of nonvariceal upper gastrointestinal hemorrhage: European Society of Gastrointestinal Endoscopy (ESGE) Guideline. Endoscopy. 2015 Oct;47(10):a1-46.

2 Schatz RA, Rockey DC. Gastrointestinal Bleeding due to Gastrointestinal Tract Malignancy: Natural History, Management, and Outcomes. Dig Dis Sci. 2017 Feb;62(2):491-501.

3 Zullo A, Hassan C, Ridola L, Repici A, Manta R, Andriani A. Gastric MALT lymphoma: old and new insights. Ann Gastroenterol. 2014;27(1):27-33.

4 Song Y, Jiang K, Su S, Wang B, Chen G. Clinical manifestations and epigenetic mechanisms of gastric mucosa associated lymphoid tissue lymphoma and long-term follow-up following Helicobacter pylori eradication. Exp Ther Med. 2018 Jan;15(1):553-61.

5 Juárez-Salcedo LM, Sokol L, Chavez JC, Dalia S. Primary Gastric Lymphoma, Epidemiology, Clinical Diagnosis, and Treatment. Cancer Contr. 2018 Jan-Mar;25(1):1073274818778256.

6 Bestari M. A rare case of severe upper gastrointestinal bleeding arising from primary gastric lymphoma. J Gastroenterol Hepatol. 2017;32(3):61-97.

7 Obleagă CV, Vere CC, Pătraşcu AM, Moraru E, Crafciuc AV, Foarfă MC, et al. Severe upper gastrointestinal bleeding determined by a gastric lymphoma associated with Helicobacter pylori-positive atrophic gastritis. Rom J Morphol Embryol. 2017;58(2):611-7.

8 Cho SH, Lee YS, Kim YJ, Sohn CH, Ahn S, Seo DW, et al. Outcomes and Role of Urgent Endoscopy in High-Risk Patients with Acute Nonvariceal Gastrointestinal Bleeding. Clin Gastroenterol Hepatol. 2018 Mar;16(3): 370-7.

9 Szura M, Pasternak A. Upper non-variceal gastrointestinal bleeding - review the effectiveness of endoscopic hemostasis methods. World J Gastrointest Endosc. 2015 Sep;7(13):1088-95.

10 Laine L, Jensen DM. Management of patients with ulcer bleeding. Am J Gastroenterol. 2012 Mar;107(3): 345-60.

11 Hu Q, Zhang Y, Zhang X, Fu K. Gastric mucosa-associated lymphoid tissue lymphoma and Helicobacter pylori infection: a review of current diagnosis and management. Biomark Res. 2016 Jul;4(1):15.

12 Violeta Filip P, Cuciureanu D, Sorina Diaconu L, Maria Vladareanu A, Silvia Pop C. MALT lymphoma: epidemiology, clinical diagnosis and treatment. J Med Life. 2018 Jul-Sep;11(3):187-93. 
Bestari et al.: Gastric MALT Lymphoma Causing Upper GI Bleeding

13 Syam AF, Miftahussurur M, Makmun D, Nusi IA, Zain LH, Zulkhairi, et al. Risk Factors and Prevalence of Helicobacter pylori in Five Largest Islands of Indonesia: A Preliminary Study. PLoS One. 2015 Nov;10(11):e0140186.

14 Hooi JK, Lai WY, Ng WK, Suen MM, Underwood FE, Tanyingoh D, et al. Global Prevalence of Helicobacter pylori Infection: Systematic Review and Meta-Analysis. Gastroenterology. 2017 Aug;153(2):420-9.

15 Zucca E, Copie-Bergman C, Ricardi U, Thieblemont C, Raderer M, Ladetto M; ESMO Guidelines Working Group. Gastric marginal zone lymphoma of MALT type: ESMO Clinical Practice Guidelines for diagnosis, treatment and follow-up. Ann Oncol. 2013 Oct;24 Suppl 6:vi144-8.

This case was presented as a poster presentation during the APDW 2016 in Kobe, Japan, and published as an abstract in the Journal of Gastroenterology and Hepatology, September 2017;32(3):61-97; the current publication adds the most recent follow-up data on the patient 


\section{Case Reports in Gastroenterology}

\begin{tabular}{l|l}
\hline Case Rep Gastroenterol 2019;13:376-384 \\
\hline DOI: 10.1159/000502795 & $\begin{array}{l}\text { ○ 2019 The Author(s). Published by S. Karger AG, Basel } \\
\text { www.karger.com/crg }\end{array}$ \\
\hline
\end{tabular}
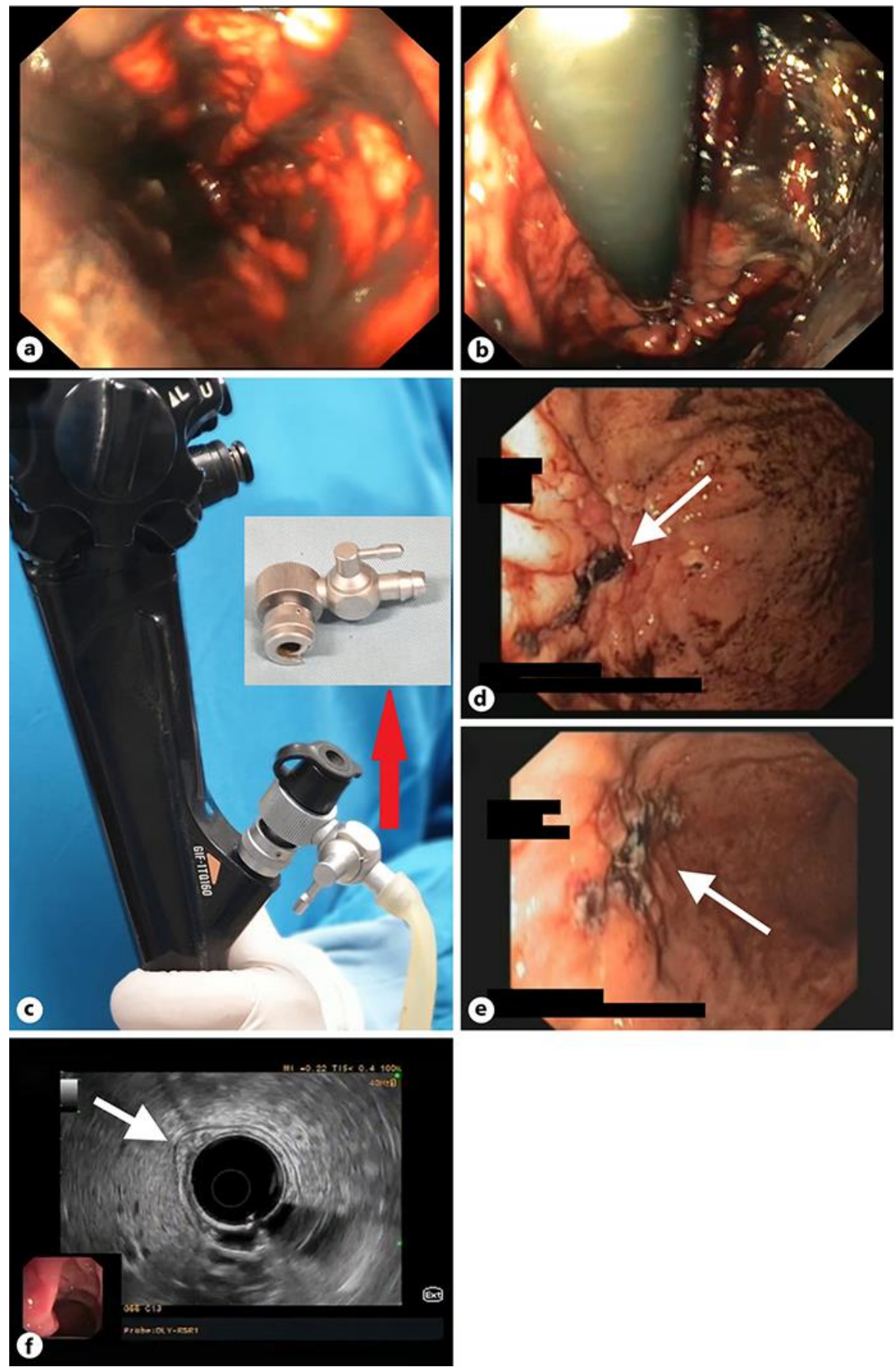

Fig. 1. Esophagoduodenoscopic images of a 75-year-old patient presenting with massive gastrointestinal bleeding. a Bleeding shown in the area of the gastric body. b Bleeding shown in the area of the gastric fundus. c Endoscopic instrument used for sucking out the blood (arrow). d Visualization after having sucked out the blood, showing oozing ulcerated polypoid masses (arrow). e Second endoscopy showing rebleeding of the ulcers 1 day after the primary endoscopy (arrow). f Endoscopic ultrasound image showing that the tumor was confined to the submucosa (arrow). 


\section{Case Reports in Gastroenterology}

\begin{tabular}{l|l}
\hline Case Rep Gastroenterol 2019;13:376-384 \\
\hline DOI: 10.1159/000502795 & $\begin{array}{l}\text { @ 2019 The Author(s). Published by S. Karger AG, Basel } \\
\text { www.karger.com/crg }\end{array}$ \\
\hline
\end{tabular}
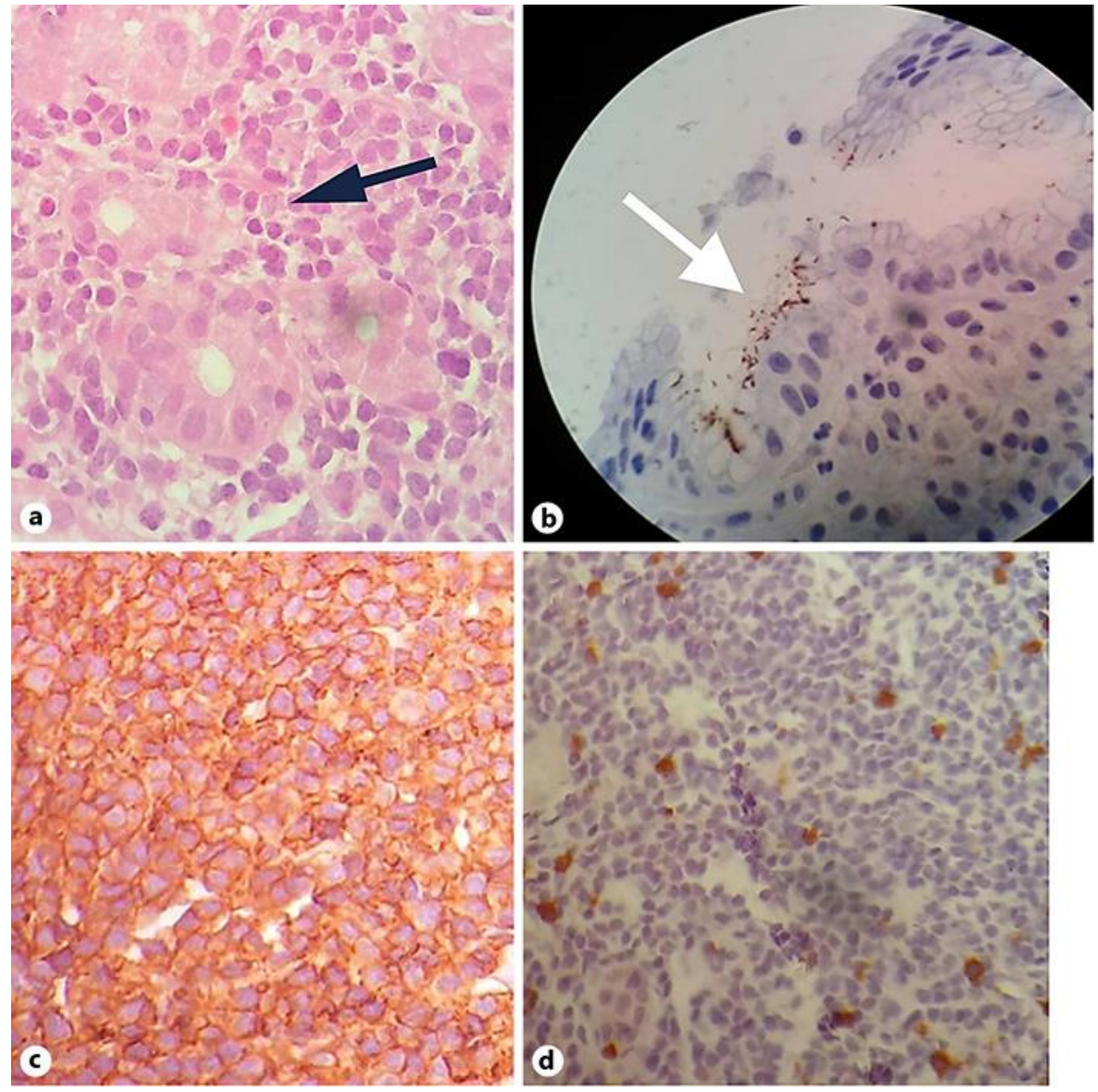

Fig. 2. Histopathologic examination of the tissue sample. a Hematoxylin-eosin stain $(\times 400)$ showing tumor cells. Diffuse large cell lymphoma (arrow). b Immunohistochemical stain $(\times 1,000)$ of the ulcer showing Helicobacter pylori (arrow). c Immunohistochemical stain with CD20 $(\times 400)$ showing diffuse immunoreaction for tumor cells. $\mathbf{d}$ Immunohistochemical stain with CD3 $(\times 400)$ showing a negative result for tumor cells. 

www.karger.com/crg

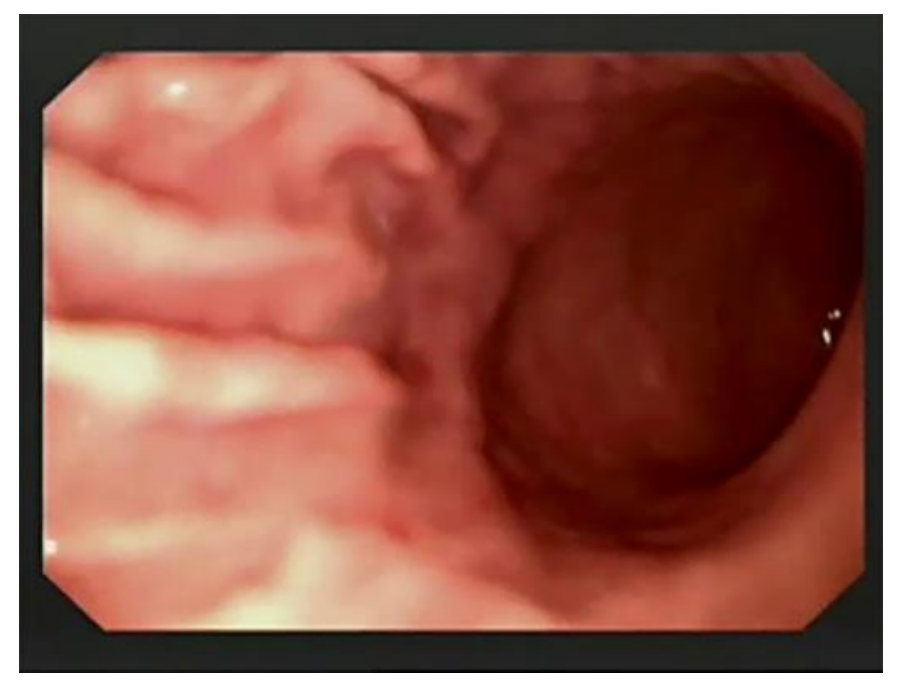

Fig. 3. Follow-up endoscopic image showing that the ulcers had healed. 